\title{
Livre Circulação de Trabalhadores e Seguridade Social - Estudo Comparado entre União Europeia e MERCOSUL, de Manuellita Hermes
}

\section{Book Review}

Osvaldo Almeida Neto ${ }^{1}$

\section{Apresentação da obra e da autora}

Manuellita Hermes é Procuradora Federal, tendo realizado estudos como pesquisadora visitante junto ao Max-Planck-Institut für Sozialrecht und Sozialpolitik /Max Planck Institute for Social Law and Social Policy em Munique, Alemanha, e o Max-Planck-Institut für ausländisches öffentliches Recht und Völkerrecht/ Max Planck Institute for Comparative Public Law and International Law em Heidelberg, Alemanha. É especialista em Justiça Constitucional e Tutela Jurisdicional dos Direitos Fundamentais pela Università di Pisa, na Itália, e em Direito do Estado pela Universidade Federal da Bahia. É Membro da Associação Internacional de Direito Constitucional - IACL/AIDC. Foi professora visitante na Università degli Studi Mediterranea di Reggio Calabria, na Itália. É autora de diversos trabalhos científicos, inclusive a obra Livre Circulação de Trabalhadores e Seguridade Social - Estudo Comparado entre União Europeia $e$ MERCOSUL, publicada em 2019 pela Editora Lumen Juris. O livro, prefaciado pelo Prof. Dr. Antônio Augusto Cançado Trindade e apresentado pelo Prof. Dr. Adriano Sant'ana Pedra, é derivado da tese de mestrado apresentada pela autora na Unversità degli Studi di Roma, "Tor Vergata", é o objeto do presente resumo.

${ }^{1}$ Procurador Federal. Doutorando e mestre em Direito pela Universidade Federal da Bahia (UFBA). Professor da UniRuy/Wyden Educacional e da Pós-Graduação da Faculdade Baiana de Direito. 


\section{Resumo}

O mundo globalizado potencializa a circulação de pessoas, inclusive trabalhadores. Livre Circulação de Trabalhadores e Seguridade Social Estudo Comparado entre União Europeia e MERCOSUL, livro de Manuellita Hermes publicado em 2019, se insere nesta temática.

No Capítulo I, Manuellita Hermes reporta como ocorreu o processo de integração regional na União Europeia e no Mercado Comum do Sul MERCOSUL, abordando, paralelamente, a influência do Direito Romano no objeto de estudo.

"O deslocamento de pessoas é recorrente na humanidade." (p.1). Cada país cria, entretanto, com base em sua soberania, critérios de admissão do ingresso de estrangeiros em seu território, inclusive para o exercício de atividades laborais. Como a questão é tratada no âmbito dos instrumentos internacionais de integração regional da União Europeia e do MERCOSUL? Existe tutela dos direitos relacionados à Seguridade Social destes trabalhadores, especialmente a aposentadoria por idade? Estes os objetivos gerais da pesquisa de Manuellita Hermes, em uma análise de direito comparado, tendo como marco metodológico da pesquisa a teoria neofuncionalista das relações internacionais mais adequado em relação a União Europeia, dado o caráter profundo de integração dos países após a segunda guerra mundial, enquanto o MERCOSUL apresenta um regionalismo aberto com ênfase em integração econômica, de exemplo do novo regionalismo da América Latina (p. 5-8).

Tanto a União Europeia como o MERCOSUL promovem a integração regional também, a partir da facilitação de deslocamento dos cidadãos nacionais entre os países do bloco. Neste sentido, "cada construção integracionista com o escopo de efetivar direitos sociais" é um instrumento de concretização da cidadania (p.10). 
A autora identifica interessantes similitudes entre o Direito Internacional Público e os institutos de Direito Romano, do jus gentium aplicável a todas as pessoas do império romano, embora difira do Direito Internacional Público porque não derivava de acordos entre Estados. O jus gentium era um sistema jurídico aberto, "que se destinava a romanos e estrangeiros, com vocação universal” (p. 15), um direito supranacional, como o que já existe, em parte na União Europeia. Ademais, a influência do Direito Romano nos ordenamentos jurídicos europeus repercute, ainda hoje, no direito comunitário. Seja na práxis do modelo jurisprudencial de solução de controvérsias, em conceitos estruturantes do sistema jurídico como a hierarquia de fontes, nos princípios gerais do direito como o suun cuique tribuere. Também os países componentes do MERCOSUL têm no direito europeu e, indiretamente, no direito romano, a base formativa de seus ordenamentos jurídicos (p. 16-18).

Manuellita Hermes traça um paralelo entre a cidadania romana e a cidadania já bem desenvolvida na União Europeia e em implantação no MERCOSUL, assegurando-se às pessoas direitos comunitários, que transcendem os direitos nacionais, ou seja, direitos vocacionados à universalidade (p. 19-20).

A autora relata todo o transcurso histórico de construção da União Europeia, desde os idealizadores de comunidades de nações baseadas na busca da paz - Abbé de St. Pierre e Kant (séc. XVII e XVIII). Passando pela Sociedade de Nações - Tratado de Versalhes, de 20 de julho de 1919; acordos econômicos, como a Convenção Monetária BENELUX - Bélgica, Holanda e Luxemburgo (1943); acordos de cooperação, como o Conselho da Europa Tratado de Londres de 5 de maio de 1949; a formação da Comunidade Europeia de Carvão e Aço - CECA, Tratado de Paris, de 18 de abril de 1951 Bélgica, Alemanha Federal, França, Itália, Holanda e Luxemburgo, mesmos países que firmaram em Roma, em 25 de março de 1957, a Comunidade Econômica Europeia - CEE, embrião da integração consolidada com o 
Tratado de Maastricht, de 7 de fevereiro de 1992, que alterou a designação de Comunidade Econômica Europeia para Comunidade Europeia, atualmente ordenada pelo Tratado de Lisboa, de 13 de setembro de 2007. Identifica os países membros originários, os atos de adesão dos membros subsequentes, além de referenciar o BREXIT - ainda em curso, como um case a ser observado quanto a salvaguarda dos direitos dos cidadãos do bloco (p. 20-32).

O MERCOSUL surgiu em 23 de março de 1991, com o Tratado de Assunção, tendo por objetivo central a integração econômica entre os países membros originários - Brasil, Argentina, Uruguai e Paraguai. A Venezuela se tornou membro do bloco em 2006, mas está desde 2017, por decisão dos demais membros, suspensa do bloco em razão de violação do Compromisso Democrático do MERCOSUL, nos termos do art. $5^{\circ}$ do protocolo de Ushuaia, assinado em 24 de julho de 1998. Atualmente, além dos países membros, participam do MERCOSUL como Estados associados Chile, Bolívia, Peru, Colômbia, Equador, Guiana e Suriname (p. 33-43).

No capítulo II Manuellita Hermes delimita de forma minuciosa o arcabouço da livre circulação de trabalhadores na União Europeia, expondo o histórico normativo e regulação atual, a amplitude do termo trabalhador e as limitações e restrições à liberdade de circulação de trabalhadores. Ressalta que "O livre trânsito de trabalhadores foi previsto desde o início do projeto integracionista, como uma forma de exportar mão de obra para o mercado comum, constituindo uma liberdade econômica em prol da formação de um nível melhor de empregabilidade, proporcionado pelo trânsito além fronteiras." Mas de um fator econômico progrediu para um direito fundamental individual com garantia de prestações devidas pelos Estados Membros, "sobretudo em relação aos direitos sociais.” (p. 45).

Instrumentos multilaterais como o Tratado de Paris de 18 de abril de 1951 - Comunidade Europeia de Carvão e Aço - CECA, e o Tratado de Roma de 25 de março de 1957 - Comunidade Europeia de Energia Atômica - 
EURATOM, já disciplinavam aspectos da circulação de trabalhadores entre os países europeus, antes da formação da Comunidade Econômica Europeia - CEE. Mas somente a partir da CEE, estabeleceu-se a livre circulação de trabalhadores vedando-se qualquer discriminação fundada na nacionalidade, conforme art. $48^{\circ}$ do seu ato constitutivo. Destaca a autora o Tratado de Maastricht, constitutivo da União Europeia instituiu, em seus arts. $8^{\circ}$ e $8^{\circ}$-A, a cidadania da União, com o direito de livre circulação e permanência no território dos Estados Membros, nos termos do Tratado e disposições adotadas na sua aplicação (p. 46-52).

Atualmente, o art. $45^{\circ}$ do Tratado sobre o funcionamento da União Europeia regula a livre circulação de trabalhadores, sendo o direito ao trabalho estabelecido no art. $15^{\circ}$ da Carta de Direitos Fundamentais da União Europeia. A Diretiva 2004/38/CE do Parlamento Europeu e do Conselho da UE, de 29 de abril de 2004 regulamenta o direito de livre circulação e residência dos cidadãos da União e dos membros das suas famílias no território dos Estados-Membros. Por fim, o Regulamento (UE) n. ${ }^{\circ}$ 492/2011 do Parlamento Europeu e do Conselho da UE, de 5 de abril de 2011, disciplina, especificamente, a livre circulação dos trabalhadores na União Europeia (p. 53-61).

A autora conclui que todo o arcabouço normativo citado "inclui, em síntese: procura de trabalho em outro Estado Membro; labor sem necessidade de visto específico; residência e permanência, mesmo após o término do trabalho, com as mesmas garantias dos nacionais do país para cesso ao emprego; condições de trabalho e outras vantagens sociais e tributárias que podem ajudar na adaptação ao país anfitrião, com exceções relativas a política e segurança púbicas, bem como nos acordos de transição para os novos países membros.” (p. 61).

Manuellita Hermes ressalta que o termo "trabalhador" para fins de circulação na União Europeia se refere ao trabalho subordinado, ainda que em regime de tempo parcial, não podendo tal conceito ser objeto de 
restrições por parte de cada Estado Membro. Por outro lado, não se aplica aos trabalhadores autônomos, conforme jurisprudência do Tribunal de Justiça da União Europeia. As diretivas são aplicáveis aos empregos públicos, com exceção de vínculos sob o regime de Direito Público em funções de salvaguarda de interesses do Estado (p. 62-69).

$\mathrm{O}$ art. $45^{\circ}$, parágrafo $3^{\circ}$ do Tratado sobre o funcionamento da União Europeia traz as limitações e restrições à livre circulação de trabalhadores: razões de ordem pública, segurança pública ou saúde pública. Embora reconheça-se aos países membros a liberdade para configuração das referidas hipóteses normativas, tratando-se de conceitos vagos sua aplicação deve observar o princípio da proporcionalidade, conforme precedentes do Tribunal de Justiça da União Europeia colacionados pela autora (p. 69-79).

$\mathrm{O}$ art. $45^{\circ}$, parágrafo $4^{\circ}$ do Tratado sobre o funcionamento da União Europeia exclui a sua aplicação em relação aos empregos na Administração Pública. Entretanto, como bem pontuado por Hermes: “[...] deve prevalecer a interpretação funcional, consistente na análise das reais funções desenvolvidas no exercício do cargo, as quais precisam ter estreita vinculação com a necessidade de salvaguardar interesses do Estado, de modo a justificar a exclusão de não nacionais [...]", trazendo decisões do Tribunal de Justiça da União Europeia consentâneos a este posicionamento. Reporta ainda a existência de restrições temporárias, exclusivamente relativas ao acesso ao mercado de trabalho, insertas nos procedimentos de adesão de novos membros (p. 79-85).

Em seguida, Manuellita Hermes discorre acerca da tutela securitária dos trabalhadores, da dimensão social e coordenação dos regimes nacionais de Seguridade Social. O marco normativo no âmbito dos países europeus é a Carta Social Europeia, adotada em Turim, em 18 de outubro de 1961. Atualmente, tem vigência a Carta Social Europeia Revista, adotada em Estrasburgo, em 3 de maio de 1996, em vigor desde $1^{\circ}$ de julho de 1999 . Em relação aos direitos sociais e trabalhistas, a autora cita ainda a Carta 
Comunitária dos Direitos Fundamentais dos Trabalhadores assinada em Estrasburgo, em dezembro de 1999. Tais instrumentos normativos não integram o acervo jurídico da União Europeia, consequentemente não tinham caráter vinculante para todos os países membros, somente os signatários dos referidos atos. Em 12 de dezembro de 2007, em Estrasburgo, os presidentes do Parlamento Europeu, do Conselho e da Comissão assinaram a Carta de Direitos Fundamentais da União Europeia, que passou a ter caráter vinculante para a UE com a vigência do Tratado de Lisboa, em dezembro de 2009, conforme art. $6^{\circ}$ do referido Tratado, aplicando-se a todos os países membros, exceto Reino Unido e Polônia que rejeitaram adesão à Carta (p. 86-90).

$\mathrm{O}$ art. $34^{\circ}$ da Carta de Direitos Fundamentais da União Europeia reconhece o direito a Seguridade e Assistência Sociais, cuja efetivação depende da coordenação entre a legislação comunitária e os ordenamentos nacionais dos Estados membros. O art. $48^{\circ}$ do Tratado de Lisboa fixa as bases desta coordenação, atualmente disciplinada pelos Regulamentos n. ${ }^{\circ} \mathrm{s}$ 883/2004 e 987/2009 (p. 91-100).

Em face do recorte do objeto de pesquisa, Manuellita Hermes analisa as regras gerais pertinentes a livre circulação de trabalhadores na Comunidade Europeia e o gozo da aposentadoria por idade.

Conforme seu art. $2^{\circ}$, o Regulamento n. ${ }^{\circ}$ 883/2004 aplica-se "aos nacionais de um Estado-Membro, aos apátridas e refugiados residentes num Estado-Membro que estejam ou tenham estado sujeitos à legislação de um ou mais Estados-Membros, bem como aos seus familiares e sobreviventes.", fixando a tutela de diversas prestações previdenciárias e assistenciais, nos termos de seu art. $3^{\circ}$, incluindo prestações por velhice. De acordo com o art. $11^{\circ}$, aplica-se a legislação do local onde exercida a atividade laborativa como regra geral e, subsidiariamente, a legislação do Estado-Membro de residência. A autora aborda diversos casos específicos como o trabalho em navios, deslocamento temporário do trabalhador entre Estados membros, 
exercício laboral em dois ou mais Estados membros, funcionários públicos, aviação civil, dentre outras especificidades. Os arts. 71 e 72 do Regulamento n. ${ }^{\circ}$ 883/2004 criam a Comissão Administrativa para a Coordenação dos Sistemas de Segurança Social, fixando suas atribuições, como órgão competente para tratar dos procedimentos administrativos no âmbito do bloco, inclusive intepretação dos instrumentos legais e promoção da colaboração entre os Estados Membros (p. 101-110).

No que refere ao benefício previdenciário da aposentadoria por idade, Manuellita Hermes discorre sobre os critérios normativos do Regulamento n. ${ }^{\circ} 883 / 2004$ acerca da contagem dos períodos de contribuição, cálculo do benefício, factível a concessão proporcional ao tempo de contribuição entre mais de um Estado Membro, valor mínimo do benefício, destacando diversos julgados do Tribunal de Justiça da União Europeia da tutela securitária e da aposentadoria por idade no âmbito do bloco. Em seguida a autora analisa a base normativa, âmbitos de aplicação pessoal e material, exemplificando com a aposentadoria por idade, benefício comum aos diversos ordenamentos. O capítulo é encerrado com a análise da jurisprudência do Tribunal de Justiça da União Europeia, sobre o tema (p. 111-119).

O Capítulo III analisa a circulação de trabalhadores no MERCOSUL. Embora o Tratado de Assunção não aborde expressamente o tema, a questão sempre esteve implícita nos objetivos do bloco, de livre circulação de fatores produtivos entre os países participantes, o que demanda a circulação de pessoas entre os países, inclusive para o exercício laboral. Nesse sentido, a circulação de trabalhadores está, atualmente, inserida no âmbito do Acordo sobre Residência para os Nacionais dos Estados Partes do MERCOSUL, Bolívia e Chile, assinado por ocasião da XXIII Reunião do Conselho do Mercado Comum, realizada em Brasília nos dias 5 e 6 de dezembro de 2002. No Brasil, o ato foi recepcionado no ordenamento interno por meio do Decreto Federal n. ${ }^{\circ}$ 6.975, de 7 de outubro de 2009 (p.121-129). 
Manuellita Hermes destaca que "São garantidos aos portadores de residência os mesmos direitos e liberdades civis dos nacionais, sendo assegurado o direito a trabalhar e exercer atividade lícita.”, destacando que a subsistência por meio lícito decorre, ordinariamente, do trabalho. Acerca da tutela previdenciária, o artigo 9.4 do referido Acordo dispõe que "As partes analisarão a exequibilidade de firmar acordos de reciprocidade em matéria previdenciária.” (p. 130-131).

A autora ressalta que a Coordenação dos Regimes de Seguridade Social entre os Estados Partes decorre ainda da justiça social como objetivo do MERCOSUL, expressa em dois atos normativos do bloco: a Declaração Sociolaboral, firmada em 10 de dezembro de 1998 no Rio de Janeiro e revisada em 17 de julho de 2015, em Brasília; e o Acordo Multilateral de Seguridade Social do MERCOSUL, firmado em 17 de dezembro de 1997, em Montevideo, durante a XIII Reunião do Conselho do Mercado Comum, com vigência a partir de $1^{\circ}$ de junho de 2005 (p. 131-135).

O Acordo Multilateral de Seguridade Social do MERCOSUL estabelece regras de coordenação entre os ordenamentos dos países membros objetivando a concessão de benefícios nos termos das respectivas legislações internas. No âmbito de aplicação pessoal o artigo $2^{\circ}$ do referido ato garante os direitos à Seguridade Social aos trabalhadores - inclusive os de países não integrantes do MERCOSUL, pela prestação de serviços em quaisquer dos Estados Partes, em igualdade de condições com os nacionais de tais Estados. Pontua a autora que não obstante o uso do termo "trabalhador", a proteção destina-se ao empregado, inclusive servidores públicos, não abrangendo o trabalhador autônomo. Aplica-se a legislação do local de exercício laboral, previstas exceções relacionadas a algumas atividades como pesquisa, pessoal de voo de empesas de transporte aéreo e de trânsito de transporte terrestre, membros da tripulação de navios. A fiscalização do cumprimento do referido acordo é atribuição da Comissão 
Multilateral Permanente integrada por até três membros de cada Estado Parte (p. 136-143).

Em relação à aposentadoria por idade, o benefício deve ser requerido à instituição competente do país membro, estabelecendo o art. $7^{\circ}$ do Acordo Multilateral de Seguridade Social do MERCOSUL a contagem dos períodos de seguro ou contribuição cumpridos nos territórios dos Estados Partes. Com base no Acordo e em seu Regulamento, veda-se o cômputo de períodos sobrepostos, admitindo-se a contagem de contribuições anteriores ao Acordo desde que tenham havidos novas contribuições após a sua vigência. Exige-se carência - número mínimo de contribuições para concessão de benefício de 12 (doze) meses, sem prejuízo da tutela securitária, em caso de período menor, com base em outros acordos bilaterais ou multilaterais firmados entre o Estado parte do MERCOSUL e um país terceiro. Na hipótese de contribuições em mais de um Estado, somados os tempos de contribuição para a concessão do benefício, o custo de seu pagamento será dividido proporcionalmente entre os respectivos países. Cada Estado parte terá um Organismo de Ligação, responsável pela certificação de tempo de contribuição, análise e concessão de benefícios no âmbito do Acordo Multilateral de Seguridade Social do MERCOSUL. No Brasil, o INSS tem uma agência especializada para atendimento de acordos internacionais, conforme Resolução INSS n. ${ }^{\circ}$ 295/2013, localizada em Florianópolis, Santa Catarina. O capítulo é encerrado com exemplos práticos de aplicação do Acordo, e alguns precedentes da jurisprudência brasileira, esclarecendo-se que o MERCOSUL não dispõe de um tribunal supranacional, como o Tribunal de Justiça da União Europeia (p. 144-164).

O capítulo IV traz o estudo comparado do objeto de pesquisa, a livre circulação de trabalhadores na União Europeia e no MERCOSUL, e a tutela securitária quanto a determinação e aplicação da legislação aplicável, totalização de períodos, proibição de cumulação de prestações, exportação da 
prestação entre os países membros ou manutenção do direito adquirido e a cooperação administrativa.

Manuellita Hermes aponta que tanto a União Europeia como o MERCOSUL "promovem a livre circulação dos trabalhadores, de modo a efetivar o princípio da liberdade.” (p.166), embora com origens históricas e desenvolvimentos distintos, destacando que no âmbito europeu há maior efetividade das normas - diretivas e regulamentos de caráter vinculante, enquanto o bloco sul-americano adota acordos sobre a matéria, que ficam sob a dependência de ratificação e incorporação nos ordenamentos dos Estados membros. A autora compara a circulação dos trabalhadores na União Europeia e no MERCOSUL sob o princípio da liberdade tendo em vista dimensões judicial, política e cívica/social, destacando a necessidade de maior atuação das duas primeiras para real efetivação da última, de forma a promover o exercício pleno dos direitos subjetivos de circulação e proteção securitária dos trabalhadores entre os países dos blocos (p. 165-176).

$\mathrm{O}$ direito à igualdade de tratamento e vedação de discriminação entre os trabalhadores nacionais e não nacionais é outro elemento de aproximação entre os dois processos regionais de integração. O princípio da igualdade aplica-se também em relação a proteção dos regimes de seguridade social. Embora mantidas as regras securitárias nacionais de cada Estado membro, os critérios de concessão dos benefícios aos nacionais devem ser os mesmos para os trabalhadores estrangeiros. Manuellita Hermes ressalta que o direito a igualdade e livre trânsito no bloco europeu precisa ser analisado de forma integrada ao conceito de cidadania da União Europeia, que confere ao cidadão do bloco direitos independentes de sua nacionalidade. Concedida a cidadania da União, sua revogação está sujeita ao princípio da proporcionalidade, passível de controle judicial pelo Tribunal Europeu. No MERCOSUL, a cidadania regional está em fase de estudos, havendo um plano de ação em curso, conforme Decisão CMC n. ${ }^{0}$ 64/10, não tendo sido 
disponibilizada, até a publicação do livro, nem mesmo um projeto normativo da proposta de regulação (p.177-194).

A autora retoma o paralelo entre a cidadania regional e a cidadania no Império Romano. À medida que o território do Império se expandia o direito foi sendo moldado para um "perene superamento das barreiras étnicas", exemplificando o argumento com o instituto da manumissio, de aquisição da cidadania; e a extensão da cidadania romana a todos os que estavam em Roma por ato do Imperador Antonio Magno Caracalla em 212 d.C., o que caracterizaria a cidadania, mais do que um vínculo com o Estado, uma ligação com a sociedade. Defende a autora que a cidadania regional já existente na União Europeia e em via de efetivação no MERCOSUL se desenvolva com base nos mesmos moldes da cidadania romana: "O objetivo almejado deve ser a formação de uma cidadania que revele o vínculo a uma verdadeira comunidade de direito, ius commune, aberta, flexível e relativa ou dual, é dizer, que conviva com a cidadania nacional, rígida, mas que dela não dependa para o gozo de direitos sociais.” (p.195-199).

Dos princípios da liberdade e igualdade emerge um terceiro princípio norteador do estudo comparado realizado pela autora: o da solidariedade, basilar da tutela da seguridade social como um direito fundamental, nos ordenamentos nacionais, em especial nos Estados democráticos de Direito e, também, no Direito Internacional, particularmente na União Europeia e no MERCOSUL. Destaca a autora que o livre trânsito de trabalhadores não seria pleno sem a garantia de direitos previdenciários. No âmbito normativo da coordenação de Seguridade Social da União Europeia e MERCOSUL Manuellita Hermes destaca como elementos comuns: a determinação e unicidade da legislação aplicável - como regra geral a lei do local de exercício da atividade laboral; a totalização de períodos de contribuição/seguro, de emprego ou residência; a vedação de cumulação de prestações, com base em um mesmo período contributivo; a exportação da prestação entre os países membros - manutenção do direto adquirido; e a cooperação administrativa, 
na análise, concessão e pagamento de benefícios, inclusive de forma pro rata (p. 200-212).

\section{Conclusão}

Livre Circulação de Trabalhadores e Seguridade Social - Estudo Comparado entre União Europeia e MERCOSUL é indicado para estudiosos do Direito Internacional, em especial quanto a origem e desenvolvimento da União Europeia e MERCOSUL. O Capítulo IV exemplifica um efetivo estudo de Direito Comparado, a partir de profícua pesquisa dos ordenamentos objeto de análise, e não meras transcrições de normas e citação de excertos de doutrinas estrangeiras. Desperta ainda o interesse de trabalhadores e juristas quanto ao tema específico - a circulação de trabalhadores na União Europeia e MERCOSUL e a tutela da Seguridade Social, com ênfase, quanto à cobertura previdenciária, na aposentadoria por idade. Pode ainda ser utilizado em programas de Metodologia de Pesquisa, pelo rigor científico seja pela evidente correlação da tese a um projeto de pesquisa bem elaborado, seja pelas fontes pesquisadas, literatura especializada nos temas abordados e precedentes de jurisprudência, associando-se, desta forma, a teoria à prática judicial, sem olvidar o exame crítico da autora. Convém ressaltar, por fim, que a obra reaviva a atualidade do Direito Romano, onde Manuellita Hermes buscou alguns dos fundamentos teóricos de seu excelente trabalho.

\section{Referência}

HERMES, Manuellita. Livre Circulação de Trabalhadores e Seguridade Social: Estudo Comparado entre União Europeia e MERCOSUL. Rio de Janeiro: Lumen Juris, 2019. 254p. 